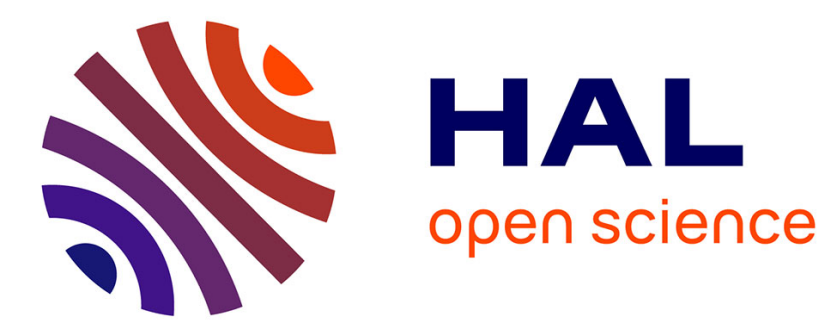

\title{
Optimal versus realized policy rules in a regime-switching framework
}

Sophie Pardo, Nicolas Rautureau, Thomas Vallée

\section{To cite this version:}

Sophie Pardo, Nicolas Rautureau, Thomas Vallée. Optimal versus realized policy rules in a regimeswitching framework. 2010. hal-00462957

\author{
HAL Id: hal-00462957 \\ https://hal.science/hal-00462957 \\ Preprint submitted on 10 Mar 2010
}

HAL is a multi-disciplinary open access archive for the deposit and dissemination of scientific research documents, whether they are published or not. The documents may come from teaching and research institutions in France or abroad, or from public or private research centers.
L'archive ouverte pluridisciplinaire HAL, est destinée au dépôt et à la diffusion de documents scientifiques de niveau recherche, publiés ou non, émanant des établissements d'enseignement et de recherche français ou étrangers, des laboratoires publics ou privés. 
EA 4272

\title{
Optimal versus realized policy rules in a regime-switching framework
}

\author{
Sophie Pardo $\left(^{*}\right)$ \\ Nicolas Rautureau $\left(^{*}\right)$ \\ Thomas Vallée $\left(^{*}\right)$
}

\section{$2010 / 11$}

(*) LEMNA - Université de Nantes

Laboratoire d'Economie et de Management Nantes-Atlantique Université de Nantes

Chemin de la Censive du Tertre - BP 52231 44322 Nantes cedex 3 - France

www.univ-nantes.fr/iemn-iae/recherche

Tél. +33 (0)2 40141717 - Fax +33 (0)2 40141749 


\title{
Optimal versus realized policy rules in a regime-switching framework
}

\author{
S. Pardo, N. Rautureau, T. Vallée ${ }^{\dagger}$
}

February 2010

\begin{abstract}
In this paper we compare a deterministic model and a Markov switching model to analyze the behavior of the US economy and the Federal Reserve. We examine both optimal and empirical monetary policies for the US Federal Reserve between 1960 and 2008. We compare the optimal monetary policy to the actual interest rates and to the empirical reaction function. We also evaluate the sensitivity of the results to the preferences assigned to each objective. We find that there is no unique optimal solution that fits the Federal Reserve behavior over the entire period. The best fit to the actual interest rates is obtained by an optimal policy with preference switches following the rule: a high-volatility regime coincides with a priority on inflation alone while in a low-volatility regime there is equal policy priority on output stabilization and inflation.
\end{abstract}

JEL codes: E42, E52, E58

Keywords: Optimal monetary policy, Markov switching

\section{Introduction}

Monetary policy under uncertainty has come under renewed interest in recent years. This movement can be explained by the need for going beyond the classical linear-quadratic framework, with only additive sources of uncertainty, to a model which accurately portrays the policymaker's decision problem. Among the different approaches, Markov switching models have proved to be an interesting tool. These models have been used in empirical literature since Hamilton's seminal papers published in 1988 and 1989. The principal contribution of this approach is the consideration of changes in time series dynamics that linear statistical models cannot capture. This is especially important when we study business cycles and economic policy over a long period (Hamilton, 2005; Davig, 2004). Concerning monetary policy, empirical studies of the Fed reaction function find various breaks in the estimated interest rate rule. For example, some of these studies link the breaks to changes in chairman (e.g. Clarida et al., 2000; Judd and Rudebusch, 1998). Markov switching models are, then, widely used to estimate the reaction function or to model the behaviour of the economy. Sims and Zha (2006)

\footnotetext{
*Corresponding author

${ }^{\dagger}$ LEMNA - University of Nantes. E-mail: sophie.pardo@univ-nantes.fr, nicolas.rautureau@univ-nantes.fr, thomas.vallee@univ-nantes.fr; Address: LEMNA - Chemin de la Censive du Tertre - B.P. 52231 - 44322 Nantes Cedex 3 - France
} 
compare a multivariate regime-switching model for monetary policy with U.S. data. They find that the best fit is obtained using time variation in disturbance variances only. AssenmacherWesche (2006) uses a Markov-switching model to estimate monetary policy reaction functions for the United-States, the United Kingdom and Germany, under the assumption of a constant economic structure. She shows that, between 1973 and early 2000, all three countries changed the weights on inflation and the output gap. Davig and Leeper (2007) generalize the Taylor principle to a monetary rule with coefficients evolving according to a Markov process.

In the optimal monetary policy literature, the use of Markov switching models is more recent and is explained by their ability to model both exogenous and endogenous regime changes. Rudebusch and Svensson (1999) underline this point and conclude, first, that questions regarding parameter uncertainty and structural stability are crucial to assess the robustness of the results, and, second, that model uncertainty is another important problem which needs addressing.

Blake and Zampolli (2006) provide two algorithms to compute the solution of a linear rational expectations model with regime shifts and a time-consistent policy. They show that these methods can be applied to decision-making processes and instrument rules, and used to handle cases where there is a difference in beliefs between policymakers and the private sector. Moessner (2006) uses a hybrid New Keynesian model with rational expectations allowing structural changes in intrinsic output persistence to determine the optimal monetary policy solution for the Euro zone. He finds that the coefficients of the optimal policy rule are state-dependent and that the relationship to transition probabilities is non-linear. Svensson and Williams (2007a) use Markov jump-linear-quadratic systems (MJLQ) to examine monetary policies. They provide an algorithm for finding the optimal policy as well as solutions for arbitrary policy functions. Svensson and Williams (2007b, 2008) adopt a similar approach but introduce learning to handle the problem of policymakers who do not know the structure of the economy. Zampolli (2006) studies optimal monetary policy in a regime-switching economy with shifts in exchange rate dynamics.

In this paper we use a Markov switching model to analyze the behavior of the US economy and the Federal Reserve. First, we use quarterly data between 1960 and 2008 to estimate a multivariate model for the US economy and a univariate reaction function for the Federal Reserve. These estimations will be made using a constant-coefficient specification and, also, a two state Markov switching specification for both the economy and the reaction function. This leads on to a comparison between the changes in monetary policy and those of the business cycle.

Then, using these estimates for the US economy, we study Fed optimal monetary policies. We first use a deterministic optimal control to obtain the optimal interest rate policy. Then, we consider the two-state Markov switching model for the US economy and we calculate a Markov switching optimal policy. We also evaluate the sensitivity of the results to the preferences assigned to each objective. We compare the optimal monetary policy to the actual interest rates and to the empirical reaction function. We carry out these comparisons for the constant case and for the two specific regimes of the Markov switching model. This approach allows us to discuss the preferences of the Federal Reserve for the different states of the economy. We find very distinct regimes over the period. In other words there is no unique optimal solution that fits the Federal Reserve behavior over the entire period. The 
best fit to the actual interest rates is obtained by an optimal policy with preference switches following the rule: a high-volatility regime coincides with a priority on inflation alone while in a low-volatility regime there is equal policy priority on output stabilization and inflation.

The remainder of this paper is organized as follows. In section 2 we present the theoretical framework. In section 3 we estimate both the model for the US economy and the Federal Reserve reaction function using quarterly data between 1960 and 2008. In section 4 we derive the theoretical optimal policies that we compare to the actual interest rate. Section 5 concludes.

\section{Theoretical framework}

\subsection{The baseline model}

We start by stating the US quarterly model in a state space representation to find the optimal policy. We consider the following regime-switching version of a backward-looking model of the US economy:

$$
\left\{\begin{array}{l}
\pi_{k+1}=a_{0}^{\theta(k)} \pi_{k}+a_{1}^{\theta(k)} \pi_{k-1}+a_{2}^{\theta(k)} \pi_{k-2}+a_{3}^{\theta(k)} y_{k}+\epsilon_{\pi, k+1} \\
y_{k+1}=b_{0}^{\theta(k)} \pi_{k}+b_{1}^{\theta(k)} \pi_{k-1}+b_{2}^{\theta(k)} \pi_{k-2}+b_{3}^{\theta(k)} y_{k}+b_{4}^{\theta(k)} i_{k}+b_{5}^{\theta(k)} i_{k-1}+\epsilon_{y, k+1}
\end{array}\right.
$$

where, $\pi_{k}$ is quarterly annualized inflation, $y_{k}$ is the output gap, $i_{k}$ is the interest rate. All variables are state-dependant, with two regimes: $\forall k,(\theta(k)) \in\{1,2\}$. The shocks $\epsilon_{\pi, k}$ and $\epsilon_{y, k}$ are independent standard normal random variables.

This model is consistent with Rudebusch and Svensson (1999). The first equation is a version of the Phillips curve, which relates inflation to a lagged output gap term and to three lags of inflation. The second equation is an aggregate-demand function. The output gap depends on its own lag, on inflation over the previous three quarters and on two lags of the short-term interest rate. We choose to implement the model with a restricted number of lags for tractability of the Markov Switching VAR (MSVAR) estimation.

In this way, the central bank takes switching probability into account when determining its optimal monetary policy. Hence, we assume that the system is driven by randomly jumping parameters. The state-space form of the US quarterly model (1) can be written as:

$$
x_{k+1}=A^{\theta(k)} x_{k}+B^{\theta(k)} u_{k}+w_{k}
$$

with $A^{\theta} \in\left\{A^{1}, A^{2}\right\}$, and $B^{\theta} \in\left\{B^{1}, B^{2}\right\}$.

The state vector is defined as follows

$$
x_{k} \equiv\left[\begin{array}{c}
\pi_{k} \\
\pi_{k-1} \\
\pi_{k-2} \\
y_{k} \\
i_{k-1}
\end{array}\right], u_{k} \equiv\left[i_{k}\right], w_{k} \equiv\left[\begin{array}{c}
\epsilon_{\pi, k+1} \\
0 \\
0 \\
\epsilon_{y, k+1} \\
0
\end{array}\right]
$$

$w_{k}$ is a vector of disturbances, and the matrices of parameters $A_{\theta}$ and $B_{\theta}$ are given by 


$$
\begin{gathered}
A^{\theta} \equiv\left[\begin{array}{ccccc}
a_{0}^{\theta} & a_{1}^{\theta} & a_{2}^{\theta} & a_{3}^{\theta} & 0 \\
1 & 0 & 0 & 0 & 0 \\
0 & 1 & 0 & 0 & 0 \\
b_{0}^{\theta} & b_{1}^{\theta} & b_{2}^{\theta} & b_{3}^{\theta} & b_{5}^{\theta} \\
0 & 0 & 0 & 0 & 0
\end{array}\right], \\
B^{\theta} \equiv \quad\left[\begin{array}{ccccc}
0 & 0 & 0 & b_{4}^{\theta} & 1
\end{array}\right]^{T}
\end{gathered}
$$

As is standard, we assume that the central bank aims at reducing inflation and output gap. Central bank preferences on inflation and output gap will be different for the two regimes. Many authors also assume that central banks smooth interest rates to reduce interest rate volatility (Rudebusch and Svensson, 1999; Svensson and Williams, 2005). As a consequence, these authors include interest rate smoothing in the cost function of the central bank. We assume that the central bank does not change the weight on the interest rates smoothing parameter between the two regimes. Hence the loss function is

$$
L=\frac{1}{2}\left(\sum_{k=1}^{N}\left(Q_{\pi, \pi}^{\theta(k)} \pi_{k}^{2}+Q_{y, y}^{\theta(k)} y_{k}^{2}+Q_{i, i}\left(i_{k}-i_{k-1}\right)^{2}\right)+Q_{\pi, \pi}^{\theta(k)} \pi_{N+1}^{2}+Q_{y, y}^{\theta(k)} y_{N+1}^{2}\right)
$$

Since : $Q_{i, i}\left(i_{k}-i_{k-1}\right)^{2}=Q_{i, i} i_{k}^{2}+Q_{i, i} i_{k-1}^{2}-2 Q_{i, i} i_{k} i_{k-1}$, the expected cost criterion is given by:

$$
J\left(x_{1}, \theta(1), N+1\right)=\frac{1}{2} E\left[\sum_{k=1}^{N}\left[\tilde{x}_{k} Q^{\theta(k)} x_{k}+\tilde{u}_{k} R u_{k}+\tilde{x}_{k} Z u_{k}\right]+\tilde{x}_{N+1} Q^{\theta(N+1)} x_{N+1}\right]
$$

with

$$
Q^{\theta(k)} \equiv\left[\begin{array}{ccccc}
Q_{\pi, \pi}^{\theta(k)} & 0 & 0 & 0 & 0 \\
0 & 0 & 0 & 0 & 0 \\
0 & 0 & 0 & 0 & 0 \\
0 & 0 & 0 & Q_{y, y}^{\theta(k)} & 0 \\
0 & 0 & 0 & 0 & Q_{i, i}
\end{array}\right]
$$

And with:

$$
R \equiv\left[Q_{i, i}\right]
$$

and

$$
Z \equiv\left[\begin{array}{c}
0 \\
0 \\
0 \\
-2 Q_{i, i}
\end{array}\right]
$$

\subsection{The optimal control solutions}

To assess the relevance of a Markov switching model to the reaction function, we first study optimal policy for a deterministic case (i.e. for time invariant parameters) and then for a jump Markov case. 


\subsubsection{The Deterministic Optimal Control Solution}

Under the deterministic assumption, no regime change is allowed. Thus all parameters are time invariant in the US quarterly model (2) and in the cost function (4). We can state the Federal Reserve reaction function as an optimal interest rate policy with a state feedback law:

$$
u_{k}=F x_{k}
$$

with

$$
F \equiv\left[\begin{array}{lllll}
f_{0} & f_{1} & f_{2} & f_{3} & f_{4}
\end{array}\right]
$$

Proposition 1 The optimal control law consistent with the constant parameters version of the cost function (4) and of the dynamic (2) is

$$
u_{k}=F_{k} x_{k}, k=0,1, . ., N
$$

where

$$
F_{k}=-\left(R+\tilde{B} P_{k+1} B\right)^{-1}\left(\tilde{B} P_{k+1} A+\tilde{Z}\right)
$$

and $P_{k}$ are determined recursively

$$
P_{k}=\left(Q+\tilde{A} P_{k+1} A\right)+\left(\tilde{A} P_{k+1} B+Z\right) F_{k}
$$

with the initial condition

$$
P_{N+1}=Q
$$

Proof.

See Pindyck $(1972,1973)$.

\subsubsection{The Markov Jump Linear Quadratic Solution}

Solutions for the optimal control problem depend on the information available to the central bank. If we assume that the central bank knows the exact current state of the economy at each period of time, the optimal solution is given by proposition 2 .

Proposition 2 The optimal control law with the cost function (4) given the dynamic (2) is

$$
u_{k}^{\theta(k)}=F_{k}^{\theta(k)} x_{k}, k=0,1, . ., N
$$

where

$$
F_{k}^{\theta(k)}=-\left[R^{\theta(k)}+\tilde{B}^{\theta(k)} G_{k}^{\theta(k)} B^{\theta(k)}-1\right]\left(\tilde{B}^{\theta(k)} G_{k}^{\theta(k)} A^{\theta(k)}+\tilde{Z}^{\theta(k)}\right)
$$

with the Riccati-like equations

$$
P_{k}^{\theta(k)}=\tilde{A}^{\theta(k)} G_{k}^{\theta(k)}\left(A^{\theta(k)}+B^{\theta(k)} L\right)+Z^{\theta(k)} L+Q^{\theta(k)}
$$

with initial condition

$$
P_{N+1}^{\theta(N+1)}=Q^{\theta(N+1)}
$$

and with

$$
G_{k}^{\theta(k)}=\sum_{i=1}^{2} p_{\theta(k)}(j, i) P_{k+1}^{\theta(k+1)}
$$

where $\operatorname{Pr}\{\theta(k+1)=j \mid \theta(k)=i\}=p_{\theta(k)}(i, j)$. 


\section{Proof.}

See Chizeck and al. (1986), Abou-Kandil and al. (1995).

In this article, we assume that the central bank only knows the probability of being in a given regime ${ }^{1}$. As a consequence, the corresponding optimal solution is a simple average of the regime-dependent solutions, given the probability of being in a particular regime. This solution is given by proposition 3 .

Proposition 3 The optimal control law with the cost function (4) given the dynamic (2) and given the probability $\operatorname{Prob}(\theta(k))$ of each regime, is

$$
u_{k}=u_{k}^{1} \operatorname{Prob}(\theta(k)=1)+u_{k}^{2}(1-\operatorname{Prob}(\theta(k)=1)), k=0,1, . ., N
$$

where the optimal solution in each regime, $u_{k}^{\theta(k)}$, is given by proposition 2.

\section{Econometric Analysis}

We estimate the Markov-switching model for the US economy (1). The coefficients can take a different value in each of the two regimes. In addition, we estimate the constant-coefficient version of the model. Then, we estimate the monetary policy rule of the Federal Reserve. We assume that the reaction function can be characterized by a Markov-switching model with two regimes. These regimes are not classified ex ante. In particular, the timing of switches is not imposed and may be different from those in the economy. We consider the following general reaction function

$$
\begin{array}{r}
i_{k}=f_{0}^{\theta(k)} \pi_{k}+f_{1}^{\theta(k)} \pi_{k-1}+f_{2}^{\theta(k)} \pi_{k-2}+f_{3}^{\theta(k)} y_{k}+f_{4}^{\theta(k)} i_{k-1}+\epsilon_{i, k}, \\
\forall k,(\theta(k)) \in\{1,2\}
\end{array}
$$

Coefficients are allowed to take a different value in each of the two regimes. Choosing to use a lagged interest rate term is compatible with the loss function (3) which takes into account interest rate smoothing ${ }^{2}$. Nevertheless, Rudebusch (2002) shows that the smoothing term, which is usually interpreted as a policy inertia component, reflects instead the persistent shocks that central banks must deal with. Rudebusch concludes that this partial adjustment measured on quarterly data, implies a high predictability of interest rates over horizons of several quarters, which is not consistent with empirical evidences.

We use quarterly data for the US economy, from the first quarter of 1960 to the fourth quarter of 2008. The interest rate $\left(i_{k}\right)$, is the four-quarter average federal funds rate from the Board of Governors. Inflation $\left(\pi_{k}\right)$ is the GDP chain-type price index in percentage terms as an annual rate, i.e. $400\left(\ln p_{k}-\ln p_{k-1}\right)$. The output gap $\left(y_{k}\right)$ is taken as $100\left(q_{k}-q_{k}^{\star}\right) / q_{k}^{\star}$, where $q_{k}$ is the current real GDP and $q_{k}^{\star}$ is the potential GDP. The data used are available from $\mathrm{BEA}$ and $\mathrm{CBO}$. All the variables were de-meaned prior to estimation, so no constants appear in the equations. We also estimated the constant-coefficient version of model (1).

\footnotetext{
${ }^{1}$ Knowing exactly the current state does not significantly improve the results.

${ }^{2}$ Dropping the smoothing term reduces the fit between the optimal policy and the real interest rate.
} 
We modify the Gauss library MSVARlib as given by Bellone (2005) to estimate our Markov switching model. This latter is recursively estimated through EM algorithm. Parameters for the constant-coefficient model are estimated using the Maximum Likelihood method. We also add the Regime Classification Measure statistics (RCM) proposed by Ang and Beckaert (2002), to measure the quality of regime classification. For two states we have

$$
R C M=400 \frac{1}{N} \sum_{k=1}^{N} p_{k}\left(1-p_{k}\right)
$$

An RCM statistic close to 0 corresponds to a good regime classification, and a value close to 100 implies that the model does not capture any information about the regimes.

\begin{tabular}{|c|c|c|c|c|c|c|c|}
\hline \multicolumn{4}{|c|}{ Philips curve } & \multicolumn{4}{|c|}{ IS curve } \\
\hline Param. & Constant & Regime 1 & Regime 2 & Param. & Constant & Regime 1 & Regime 2 \\
\hline$a_{0}$ & $\begin{array}{l}0.554 \\
(0.07)\end{array}$ & $\begin{array}{c}0.388 \\
(0.096)\end{array}$ & $\begin{array}{c}0.643 \\
(0.120)\end{array}$ & $b_{0}$ & $\begin{array}{c}0.015 \\
(0.052)\end{array}$ & $\begin{array}{c}0.028 \\
(0.068)\end{array}$ & $\begin{array}{c}0.030 \\
(0.095)\end{array}$ \\
\hline$a_{1}$ & $\begin{array}{c}0.145 \\
(0.083)\end{array}$ & $\begin{array}{c}0.235 \\
(0.099)\end{array}$ & $\begin{array}{c}0.062 \\
(0.147)\end{array}$ & $b_{1}$ & $\begin{array}{c}-0.033 \\
(0.061)\end{array}$ & $\begin{array}{c}-0.040 \\
(0.059)\end{array}$ & $\begin{array}{c}-0.033 \\
(0.100)\end{array}$ \\
\hline$a_{2}$ & $\begin{array}{c}0.256 \\
(0.073)\end{array}$ & $\begin{array}{c}0.313 \\
(0.095)\end{array}$ & $\begin{array}{c}0.274 \\
(0.126)\end{array}$ & $b_{2}$ & $\begin{array}{l}-0.020 \\
(0.054)\end{array}$ & $\begin{array}{l}-0.125 \\
(0.059)\end{array}$ & $\begin{array}{c}0.058 \\
(0.095)\end{array}$ \\
\hline$a_{3}$ & $\begin{array}{c}0.115 \\
(0.033)\end{array}$ & $\begin{array}{c}0.068 \\
(0.038)\end{array}$ & $\begin{array}{c}0.180 \\
(0.083)\end{array}$ & $\begin{array}{l}b_{4} \\
b_{5}\end{array}$ & $\begin{array}{c}0.902 \\
(0.025) \\
0.133 \\
(0.062) \\
-0.197 \\
(0.061)\end{array}$ & $\begin{array}{c}0.870 \\
(0.870) \\
0.276 \\
(0.092) \\
-0.238 \\
(0.088)\end{array}$ & $\begin{array}{c}0.928 \\
(0.064) \\
0.061 \\
(0.098) \\
-0.220 \\
(0.100)\end{array}$ \\
\hline$\sigma_{\pi}$ & $\begin{array}{c}1.049 \\
(0.053)\end{array}$ & $\begin{array}{c}0.618 \\
(0.089)\end{array}$ & $\begin{array}{c}1.807 \\
(0.400)\end{array}$ & $\sigma_{y}$ & $\begin{array}{c}0.765 \\
(0.039)\end{array}$ & $\begin{array}{c}0.221 \\
(0.051)\end{array}$ & $\begin{array}{c}1.046 \\
(0.269)\end{array}$ \\
\hline$\sigma_{\pi, y}$ & $\begin{array}{c}-0.015 \\
(0.055)\end{array}$ & $\begin{array}{c}-0.043 \\
(0.036)\end{array}$ & $\begin{array}{c}0.064 \\
(0.166)\end{array}$ & & & & \\
\hline
\end{tabular}

Table 1: Estimates of the US quarterly model

Table 1 shows our estimates for the Markov-switching model and for the constant-coefficient version of the US quarterly model. Parameters for the constant coefficients version lie mainly between the range of those estimated for the two states of the Markov switching model. Our estimates for the constant-coefficient version are also close to those of Svensson and Williams (2005). In the constant case and for both state estimates in the MSVAR specification, the sum of the coefficients for inflation is close to 1, which is close to a vertical Philips curve in the long run. The RCM statistics shows a good regime classification and each regime is highly persistent.

The estimated transition matrix $P$ is given by

$$
P=\left[\begin{array}{ll}
0.957 & 0.043 \\
0.058 & 0.942
\end{array}\right]
$$

The average persistence is $1 /\left(1-p_{11}\right)=23.2558$ quarters for regime 1 and $1 /\left(1-p_{22}\right)=$ 17.2414 quarters for regime 2. Regime 2 is characterized by a higher level of inflation and a 
higher volatility both for inflation and output gap. The variances in inflation and output gap are respectively equal to 1.807 and 1.046 in regime 2 against 0.618 and 0.221 in regime 1 . The covariance between these two series is equal to 0.064 in regime 2 against -0.043 in regime 1 . Here after, we refer to regime 2 of the economy as the high-volatility regime, and to regime 1 as the low-volatility regime.

\begin{tabular}{cccc}
\hline Parameters & Constant & Regime 1 & Regime 2 \\
\hline$f_{0}$ & 0.117 & -0.025 & 0.195 \\
& $(0.059)$ & $(0.033)$ & $(0.122)$ \\
$f_{1}$ & -0.058 & 0.089 & -0.189 \\
& $(0.068)$ & $(0.034)$ & $(0.155)$ \\
$f_{2}$ & 0.086 & 0.077 & 0.132 \\
& $(0.062)$ & $(0.033)$ & $(0.131)$ \\
$f_{3}$ & 0.134 & 0.102 & 0.178 \\
& $(0.028)$ & $(0.014)$ & $(0.066)$ \\
$f_{4}$ & 0.914 & 0.895 & 0.941 \\
& $(0.027)$ & $(0.015)$ & $(0.059)$ \\
$\sigma$ & 0.886 & 0.081 & 1.888 \\
& $(0.045)$ & $(0.015)$ & $(0.344)$ \\
& & & \\
\hline Standard errors in parentheses. &
\end{tabular}

Table 2: Estimates of the Federal Reserve Reaction Function

Table 2 shows the estimates for a regime dependant reaction function and for the constant parameters version. Again, parameters for the latter model lie mainly between those estimated for the two states of the Markov switching specification. Estimates show a stronger reaction by the Federal Reserve to inflation and to economic activity in regime 2, which is characterized by a higher volatility (the residual variance is 0.081 for regime 1 against 1.888 for regime 2 ).

The RCM statistics value also illustrates a good regime classification and the interest of using the Markow switching model over the period 1960 - 2008. The estimated transition matrix $P$ for this model is

$$
P=\left[\begin{array}{ll}
0.924 & 0.076 \\
0.125 & 0.875
\end{array}\right]
$$

Hence the persistence of regime 1 is higher with an average of 13.16 quarters against 8 quarters for regime 2. The weaker persistence of regimes for the reaction function, compared to that observed for the economy could be related, to the reactivity of the Federal Reserve. 


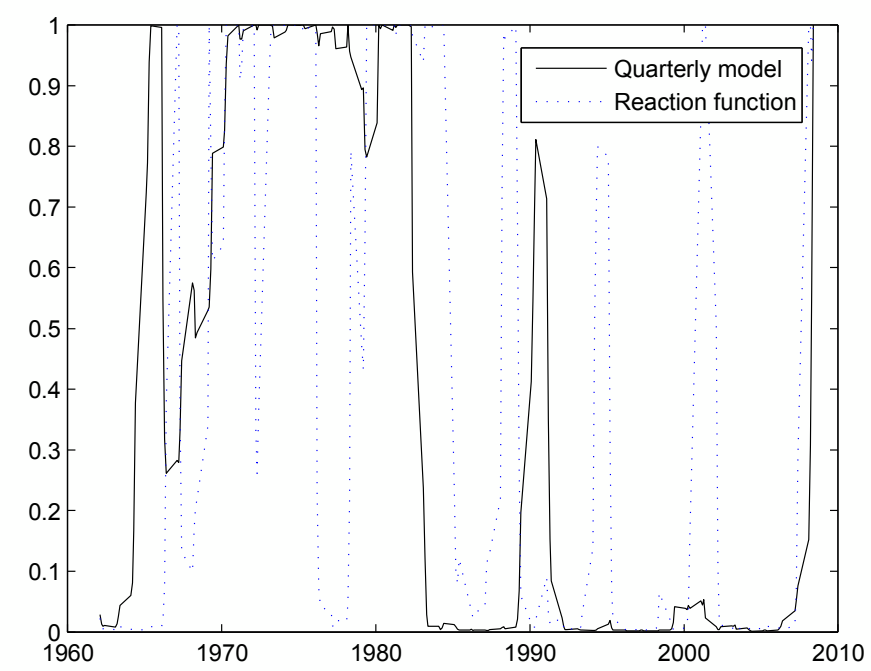

Figure 1: Probability of the high-volatility regime of the economy and probability of regime 2 of the reaction function

The estimated probabilities of the high-volatility regime for the quarterly model and for the regime 2 for the reaction function are shown in Figure 1. We can see that regime 2 of the reaction function is less persistent than the high-volatility regime of the US economy. There are two distinct periods between 1960 and 2008. The high-volatility regime of the economy dominates up until the fourth quarter of 1982, when it is superseded by the low-volatility regime for the rest of the period. This regime switch occurs at approximately the end of the Volcker experiment. In comparison, regime 1 occurs only in the first quarter of 1985 for the reaction function of the Federal Reserve, nine quarters after the switch to the low-volatility regime for the US quarterly model.

On the second part of the sample, the switch in regime 2, the more interventionist regime, occurs in the third quarter of 1988 for the reaction function, seven quarters before the economic downturn associated with the bursting of the real-estate bubble at the beginning of the 90's. The reaction function switches once again to regime 2 in 2001 with the very strong decline in the US intervention rates. During this year, the Federal Funds rate was reduced eleven times. It started the year, on January 3 , at $6 \%$ to fall to $1.75 \%$ by December 11 . Finally, the subprime mortgage crisis that began in August 2007, led to a switch of the reaction function in early 2008. The Federal Reserve dropped the Federal Funds rate from 5.25\% in June 2007 to $2.25 \%$ at the end of March 2008. At this time the spread between Fed Funds rate and the discount rate was only $0.25 \%$ instead of the usual $1 \%$. The US economy switches to the high-volatility regime two quarters later.

Table 2 shows that the sum of coefficients on inflation is less than one. This result runs counter to Taylor's rule and could be explained by the use of one lag on interest rates in (9). With the use of this lag the persistence of the interest rate dynamics captures also the reaction to inflation over many periods. Table 3 shows our estimates for the reaction function without any lag in the interest rate as in the Taylor (1993) model. Once again, coefficients for the constant model are between those estimated for the two regimes of the Markov switching 
specification. While the reaction to output gap is consistent with Taylor's rule in regime 1 $\left(f_{3}=0.495\right)$, in regime 2 the coefficient is along way off. In the less volatile regime, inflation has no need of particular attention and the Federal Reserve policy should focus mainly on economic activity. In the more volatile regime, inflation could cause trouble and the Federal Reserve should direct its action towards inflation. However, if the reaction to inflation in regime 2 is stronger than the one estimated using lag in the interest rate, it does not fit Taylor predictions (sum of $f_{0}, f_{1}, f_{2}$ equal to 1.003). This could be explained by the period including the current financial crisis. To support this argument, we have estimated the reaction function over a shorter period, ending in 2006. In this case, the values predicted by Taylor are observed for inflation in regime 2 and for output gap in regime 1, 1.583 and 0.611 . In fact, Taylor predicted coefficients values are achieved with a classic version of the reaction function but not simultaneously in each regime. These results support the use of Markov switching models and the need to take into account structural instability of the reaction function.

\begin{tabular}{cccc}
\hline Parameters & Constant & Regime 1 & Regime 2 \\
\hline$f_{0}$ & 0.310 & 0.307 & 0.351 \\
& $(0.155)$ & $(0.125)$ & $(0.198)$ \\
$f_{1}$ & 0.201 & 0.286 & 0.170 \\
& $(0.180)$ & $(0.136)$ & $(0.230)$ \\
$f_{2}$ & 0.522 & 0.514 & 0.482 \\
& $(0.161)$ & $(0.132)$ & $(0.204)$ \\
$f_{3}$ & 0.068 & 0.495 & -0.078 \\
\multicolumn{4}{c}{ Standard errors in parentheses } \\
& $(0.073)$ & $(0.065)$ & $0.099)$ \\
\hline
\end{tabular}

Table 3: Estimates of the Federal Reserve Reaction Function without lag in the interest rate 


\section{The optimal reaction function}

In this section we compare the optimal monetary policy and the actual interest rate for both the constant case and for the two specific regimes of the Markov switching model. The optimal control problem is consistent with Propositions 1 to 3 and we obtain solutions for the deterministic and the Markov Jump Linear Quadratic cases.

\subsection{Deterministic cases}

In the deterministic case no regime switch is allowed. In particular, central bank preferences for inflation and output stabilization remain constant over the entire period. We previously assume that the interest rate smoothing parameter is not allowed to switch. The weights $Q_{\pi_{k}, \pi_{k}}, Q_{y_{k}, y_{k}}$ and $Q_{i, i}$ represent Federal Reserve preferences on inflation, output stabilization and interest rate smoothing. As in Rudebusch and Svensson (2002), we set the central bank's preferences exogenously. Consistent with much of the empirical literature, we assign a significant weight to interest rate smoothing ${ }^{3}$. Assuming a constant weight on interest rate smoothing $Q_{i, i}=1$, we define three different sets of parameters for inflation and output stabilization. We define equal priority as $Q_{\pi_{k}, \pi_{k}}=Q_{y_{k}, y_{k}}=1$; inflation priority as $Q_{\pi_{k}, \pi_{k}}=2$, $Q_{y_{k}, y_{k}}=1$ and output gap priority as $Q_{\pi_{k}, \pi_{k}}=1, Q_{y_{k}, y_{k}}=2$. Equal priority corresponds to the flexible inflation targeting examined in Rudebusch and Svensson (2002), with equal weight on both inflation and output. In addition, we allow flexible inflation targeting ${ }^{4}$ putting a higher weight on one of the variables.

We first consider a mean case with no distinction between the two possible states of the economy. Given the constant estimates of the US quarterly model (first column of table 1), we compute the Federal Reserve optimal reaction function (6) using different sets of priorities. We compare stable values of the reaction function $F$ (table 4 ) to the empirical reaction function (9), estimated in the constant case (first column of table 2).

\begin{tabular}{c|cc|ccccc}
\cline { 2 - 7 } & $Q_{\pi_{k}, \pi_{k}}$ & $Q_{y_{k}, y_{k}}$ & $f_{0}^{\text {opt }}$ & $f_{1}^{\text {opt }}$ & $f_{2}^{\text {opt }}$ & $f_{3}^{\text {opt }}$ & $f_{4}^{\text {opt }}$ \\
\hline Output gap priority & 1 & 2 & 0.0830 & 0.0099 & 0.0148 & 0.6104 & 0.5186 \\
Equal priority & 1 & 1 & 0.1465 & 0.0406 & 0.0322 & 0.5050 & 0.5956 \\
Inflation priority & 2 & 1 & 0.2845 & 0.0929 & 0.0669 & 0.6232 & 0.5580 \\
\hline
\end{tabular}

Table 4: Optimal reaction function for different central bank priorities. Constant case.

The Federal Reserve reaction appears to be generally more cautious than the theoretical optimal ones. Indeed, estimates of parameters on inflation and output gap are overall weaker than the theoretical optimal ones. Table 4 shows that the sum of coefficients on inflation $\left(f_{0}^{o p t}, f_{1}^{o p t}, f_{2}^{o p t}\right)$ increases with the inflation priority of the central bank. The inertia of the central bank is reflected by the high value estimated for $i_{k-1}$. The theoretical optimal relation implies less inertia with a lower value of $f_{4}^{o p t}$ and this is robust to the different sets of priorities.

Graphical comparison between historical interest rate values and theoretical optimal ones, is provided in appendix A. Figure A.1 shows that the theoretical optimal reaction function

\footnotetext{
${ }^{3}$ Among others, we can cite Favero and Rovelli, 2003; Dennis, 2004, 2006; Ozlale, 2003.

${ }^{4}$ See Rudebusch and Svensson, 1999; Svensson, 1999.
} 
with priority on output gap fails to fit the historical interest rate. The discrepancy substantially increases over the period 1980-2000, as illustrated in panel (a) of figure A.2. This result is consistent with empirical studies of the Federal Reserve's preferences, which find little priority given to output stabilization (Favero and Rovelli, 2003, Ozlale, 2003, Dennis, 2006). In particular, Dennis (2006) shows that the relative weight on the output gap is statistically insignificant over the period 1982Q1-2000Q2. Assuming an equal level of priority on inflation and output gap slightly improves the fit without leading to a convincing one. It is clearly a high priority on inflation that gives a better fit with the historical interest rate over the entire $\operatorname{period}^{5}$ (panel b). This priority increased at the beginning of the 80's while the economy was in the more volatile regime. To confirm this result we put a higher weight on inflation priority, which improves the fit over this period. We calculate the cumulative sum of absolute deviation between one-step ahead prediction and the historical interest rate for inflation priority $\left(Q_{\pi_{k}, \pi_{k}}=2\right)$ and very high inflation priority $\left(Q_{\pi_{k}, \pi_{k}}=5\right)$. The slope of this function is lower for the very high inflation priority over this period (panel (c)). However, it does not lead to a convincing fit.

We now specify a particular regime for the economy, which could represent expectations made by the central bank about the state of the economy. Under the assumption of a deterministic model, there is no possible switch to another regime. Assuming that the economy remains in the low-volatility regime and given the estimates of the US economy in this regime (column 2 of table 1), we calculate the optimal reaction function for different sets of preferences. Table 5 summarizes the optimal reaction functions, which we compare to the estimated reaction function for regime 1 (column 2 of table 2 ).

\begin{tabular}{c|cc|ccccc}
\cline { 2 - 7 } & $Q_{\pi_{k}, \pi_{k}}$ & $Q_{y_{k}, y_{k}}$ & $f_{0}^{\text {opt }}$ & $f_{1}^{\text {opt }}$ & $f_{2}^{\text {opt }}$ & $f_{3}^{\text {opt }}$ & $f_{4}^{\text {opt }}$ \\
\hline Output gap priority & 1 & 2 & -0.0076 & 0.0546 & 0.0677 & -0.7983 & 0.8740 \\
Equal priority & 1 & 1 & -0.0329 & 0.0687 & 0.0949 & -0.8146 & 0.8932 \\
Inflation priority & 2 & 1 & -0.0181 & 0.0303 & 0.0397 & -0.3693 & 0.9148 \\
\hline
\end{tabular}

Table 5: Optimal reaction function for different central bank priorities. Low-volatility regime.

Table 5 shows that the optimal policies react negatively to the current values of inflation $\left(f_{1}^{o p t}\right)$ and of output gap $\left(f_{3}^{o p t}\right)$. It is noticeable that in case of equal priority, there is a stronger reaction to both output gap and inflation than in the other cases. Because the low-volatility regime is more stable, the theoretical optimal function implies a high inertia level $f_{4}^{o p t}$ which is close to the estimated parameter for $i_{k-1}$, whatever the preferences are. Figure A.3 shows that, if the central bank acts as if the economy remains in the low-volatility regime, optimal policy with equal priority gives the best fit overall. This result is confirmed by the cumulative sum of absolute deviation between one-step ahead prediction and the realized interest rate (see figure A.4). Interestingly, panel (b) of figure A.4 shows that an inflation priority policy and an output gap priority policy give very close results. To look further at the results we focus on the main period of the low-volatility regime for the economy, which starts at the end of 1982. Figure A.5 shows the cumulative sum of absolute deviation between one-step ahead prediction and the realized interest rate on the low-volatility regime (during the period corresponding to the high-volatility regime, this cumulative sum does not increase). Panel (a)

\footnotetext{
${ }^{5}$ This result is consistent with Ozlale (2003) who shows that the FED puts more emphasis on price stability than output stability when considering the entire period 1970:Q1-1999:Q1. Priorities are different when considering the sub-periods corresponding to each of the three different administrations.
} 
confirms the superiority of the equal priority policy and the gap increases after 2000. Panel (b) shows that if the Federal Reserve anticipates the stable regime for the economy, and it is in the low-volatility regime, then inflation priority gives a slightly better fit than output gap priority. This result is consistent with Assenmacher-Wesche (2006), who assumes that a more aggressive policy towards inflation is conducive to a more stable regime (and vice versa).

Assuming now that the economy is always in the high-volatility regime, and given the estimates of the US economy in this regime (column 3 of table 1), we calculate the optimal reaction function for different sets of priorities. Table 6 gives the optimal reaction functions that we compare to the estimated reaction function for regime 2 (column 3 of table 2).

\begin{tabular}{c|cc|ccccc}
\cline { 2 - 7 } & $Q_{\pi_{k}, \pi_{k}}$ & $Q_{y_{k}, y_{k}}$ & $f_{0}^{\text {opt }}$ & $f_{1}^{\text {opt }}$ & $f_{2}^{\text {opt }}$ & $f_{3}^{\text {opt }}$ & $f_{4}^{\text {opt }}$ \\
\hline Output gap priority & 1 & 2 & 0.4619 & 0.1674 & 0.1778 & 1.0208 & 0.2709 \\
Equal priority & 1 & 1 & 0.4827 & 0.1705 & 0.1751 & 0.8683 & 0.3551 \\
Inflation priority & 2 & 1 & 0.3691 & 0.1299 & 0.1335 & 0.6564 & 0.4562 \\
\hline
\end{tabular}

Table 6: Optimal reaction function for different central bank priorities. High-volatility regime.

The estimated reaction function appears to be generally more conservative than the optimal policies and exhibits a stronger inertia. Estimated parameters for the past interest rate are even higher than in the two other cases. On the other hand, optimal coefficient on lagged interest rate $\left(f_{4}^{\text {opt }}\right)$ is lower, which is consistent with the high-volatility regime of the economy. Table 6 also shows that in this case, the coefficient on output gap $\left(f_{3}^{\text {opt }}\right)$ increases with the prioritization of output gap. Figure A.6 compares the optimal reaction function and the real values of the interest rate. Output gap priority fails to produce a fit with these real values. Figure A.7 traces the cumulative sum of absolute deviation. If the Federal Reserve acts as if the economy was in the high-volatility regime, it appears it would be optimal to put equal priority on inflation and on output gap (panels (a) and (b)). Panel (c) highlights a break that occurs in 1982. Before this date, output gap stabilization is prioritized over inflation. When the economy switches to the low-volatility regime and assuming that Federal Reserve goes on anticipating a more volatile regime, a priority on inflation leads to a better fit. Again, consistent with Assenmacher-Wesche (2006), maintaining an aggressive policy towards inflation leads to a more stable regime. Focusing now on the period where the economy is in the high-volatility regime, panel (a) of figure A.8 illustrates that during the Volcker experiment, maintaining an equal priority on inflation and output gap limits the deviation from the historical interest rate.

\section{Monte Carlo Analysis}

We run a Monte Carlo analysis to underline how a change in weights modifies the discrepancy between our theoretical results and the empirical ones. We draw 50,000 times the $q_{i j} \in[0.1,10]$ and we calculate the error $\Sigma \equiv \sum_{t}\left(u_{t}-u_{t}^{*}\right)^{2}$ where $u$ is the realized reaction function and $u^{*}$ is the optimal one. Figure 2 shows the mean error in each previous case: the constant case, the low-volatility regime and the high-volatility regime. 
Determinist Constant Case

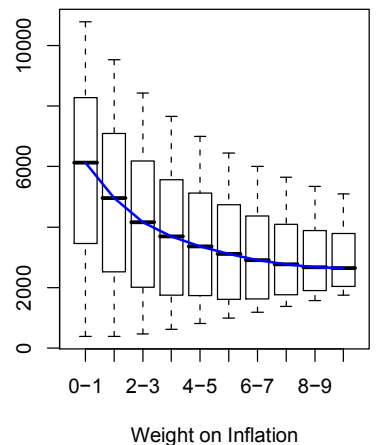

Determinist Regime 1 Case

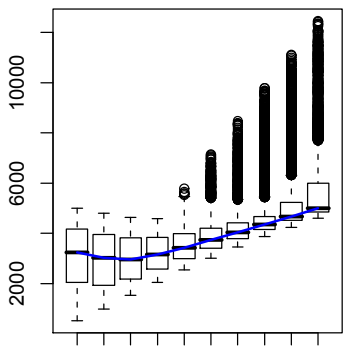

$\begin{array}{lllll}0-1 & 2-3 & 4-5 & 6-7 & 8-9\end{array}$

Weight on Inflation in Regime 1

Determinist Regime 2 Case

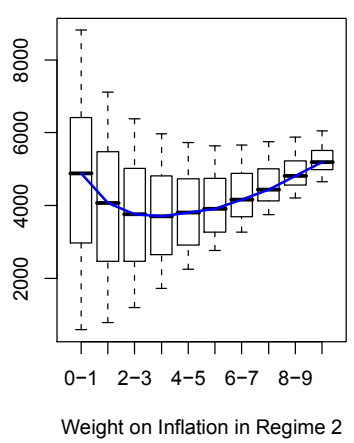

Determinist Constant Case

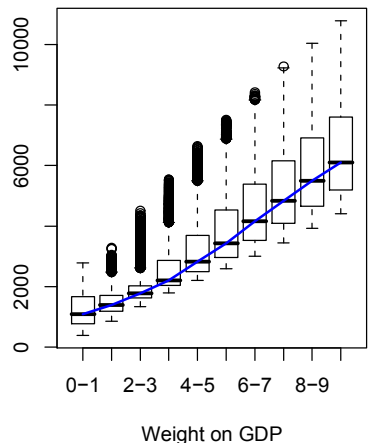

Determinist Regime 1 Case

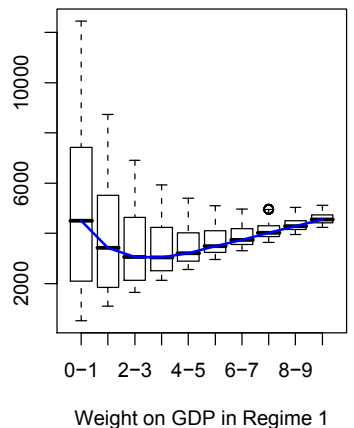

Determinist Regime 2 Case

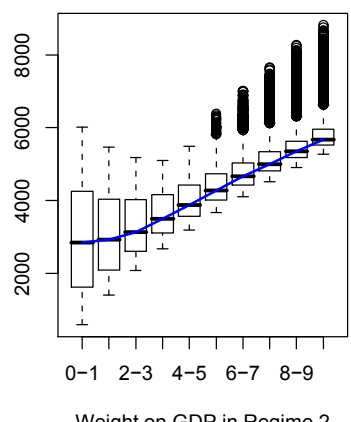

Figure 2: Monte Carlo simulation. Mean error between optimal and realized reaction function: (a) constant case (top), (b) low-volatility regime (center), (c) high-volatility regime(bottom)

The results obtained using Monte Carlo simulations for the constant case and the lowvolatility regime, are consistent with previous optimal reaction functions, as shown in figure 2 . In the first case, with no distinction between regimes, panel (a) confirms that increasing the weight on inflation while reducing the weight on output gap reduces the discrepancy between our theoretical results and the empirical ones. In this case, an inflation priority dominates. When the economy is in the low-volatility regime, combining equal weights on inflation and output gap leads to the best result as seen in panel (b). Results obtained when the economy 
stays in the high-volatility regime, are more qualified. In panel (c) we can see that a higher weight on inflation than on output gap seems to give a better result, while previous results support equal weighting. Using only one pair of weights ( 2 for inflation and 1 for output gap) against equal priority is not sufficient to explain the behavior of the optimal reaction function.

The results of this section show that the optimal solution over the period is not consistent with the optimal solution for each regime taken separately. Hence, we need to allow for a change in central bank priorities using a Markov-switching model.

\subsection{The MJLQ case}

We now calculate the optimal reaction function in a MJLQ case, using different sets of preferences. In this case, the optimal policy is computed given a Markov-switching model of the US economy. We use estimates for the two regimes given in table 1.

Following proposition 3, the optimal MJLQ control is defined as

$$
u_{k}^{*}=\operatorname{Pr}_{(1,1), k} u_{k}^{1}+\operatorname{Pr}_{(1,2), k} u_{k}^{2}
$$

where $\operatorname{Pr}_{k}$ is given by the evolution of the transition probabilities matrix

$$
\operatorname{Pr}_{k+1}=\operatorname{Pr}_{0} \operatorname{Pr}_{k}
$$

with $P r_{0}$ the initial transition probabilities matrix defined by the estimated probabilities of the Markov-switching version of the US quarterly model

$$
\operatorname{Pr}_{0}=\left[\begin{array}{ll}
0.957 & 0.043 \\
0.058 & 0.942
\end{array}\right]
$$

Figure 3 shows that after a sufficient number of periods, the transition probabilities matrix converges to the following stable transition probabilities ${ }^{6}$

$$
\operatorname{Pr}^{*}=\left[\begin{array}{ll}
0.5743 & 0.4257 \\
0.5743 & 0.4257
\end{array}\right]
$$

\footnotetext{
${ }^{6} \operatorname{Pr} *$ is the unique solution to $\operatorname{Pr}{ }^{*}=\operatorname{Pr} P r^{*}$.
} 


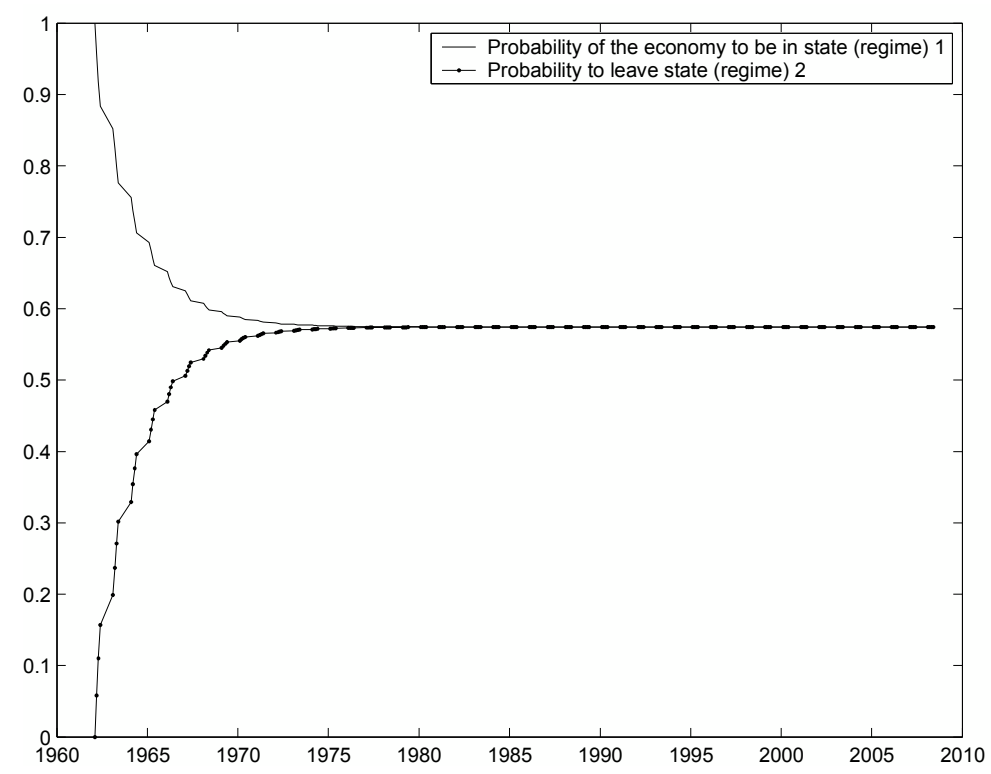

Figure 3: Evolution of the probability of the low-volatility regime of the economy

As in the deterministic case, we consider three possible sets of policy preference parameters. The neutral case gives equal priority to inflation and output gap whatever the regime. In the two other cases, the central bank changes its priorities among the regimes. First, we assume output priority in the low-volatility regime and inflation priority in the high-volatility regime. We refer to this case as "output-low/inflation-high". Conversely in case "inflation-low/ outputhigh", we give priority to inflation in the low-volatility regime and to output stabilization in the high-volatility regime. We use the following weights for the simulations

- Neutral case: $Q_{\pi, \pi}=1=Q_{y, y} \forall \theta(k)$.

- output-low/inflation-high: $Q_{\pi, \pi}=1$ and $Q_{y, y}=2$ if $\theta(k)=1$ and $Q_{\pi, \pi}=2$ and $Q_{y, y}=1$ if $\theta(k)=2$.

- inflation-low/output-high: $Q_{\pi, \pi}=2$ and $Q_{y, y}=1$ if $\theta(k)=1$ and $Q_{\pi, \pi}=1$ and $Q_{y, y}=2$ if $\theta(k)=2$.

Table 7 gives the optimal stable values of the reaction function ${ }^{7}, F=\operatorname{Pr}_{1,1}^{*} F^{\theta(k)=1}+$ $\operatorname{Pr}_{1,2}^{*} F^{\theta(k)=2}$, and figure B.1, in appendix B gives the results of these simulations.

\begin{tabular}{|c|ccccc|}
\hline$F$ & $f_{0}^{\text {opt }}$ & $f_{1}^{\text {opt }}$ & $f_{2}^{\text {opt }}$ & $f_{3}^{\text {opt }}$ & $f_{4}^{\text {opt }}$ \\
Neutral case & 0.1625 & 0.0809 & 0.0963 & 0.0754 & 0.6657 \\
output low/inflation high & 0.2227 & 0.1176 & 0.1352 & -0.0178 & 0.6451 \\
inflation low/ output high & 0.1220 & 0.0570 & 0.0887 & 0.1287 & 0.6263 \\
\hline
\end{tabular}

Table 7: Stable values of the reaction function

The optimal coefficient on lagged interest rates $\left(f_{4}^{o p t}\right)$ is slightly higher than those calculated in deterministic cases and thus, is closer of the realized behavior. On the other hand,

\footnotetext{
${ }^{7}$ We take the stable elements of $F$, that is the values of $F$ before the end of the world effect plays.
} 
the optimal coefficient on output gap $\left(f_{3}^{\text {opt }}\right)$ is lower than in deterministic case which means that the optimal policy driven by a MJLQ model reacts more weakly to the GDP than that driven by a deterministic one.

Figure B.1 compares the realized interest rate and the optimal policy. We can observe in panel (c) that an optimal policy that gives priority to output gap in the high-volatility regime and to inflation in the low-volatility regime fails to fit the data. The "output-low/inflationhigh" (panel (b)) and neutral (panel (a)) cases improve the results significantly. This is confirmed by the cumulative sum of absolute deviation given in figure B.2. Moreover, we can observe that "output-low/inflation-high" dominates overall, even this is less evident at the beginning of the period. Finally we combine the two cases as "equal-low/inflation-high", setting equal priority on inflation and output gap in the low-volatility regime and priority on inflation in the high-volatility regime. This means that we reduce the relative weight of the output gap over the low-volatility regime. The cumulative sum of absolute deviation is given in figure B.3 and is compared to the results obtained using only "output-low/inflation-high" weights. We also give the results for the inverse combination (output-low/equal-high). We clearly see that the combination "equal-low/inflation-high" gives the best results. In conclusion, using a MJLQ optimal policy improves the data fit, compared to the previously-seen deterministic cases. This confirms the relevance of allowing a switch of preferences for the different regimes according to the following rule: a high-volatility regime puts priority on inflation while equal priority on output gap and inflation is better in a low-volatility regime.

\section{Monte Carlo Analysis}

As in the deterministic case, we run a Monte Carlo simulation to underline how a change of weights modifies the discrepancy between the optimal reaction function and the empirical one. As previously, we draw 50,000 times the $q_{i j} \in[0.1,10]$ and we calculate the error $\Sigma \equiv$ $\sum_{t}\left(u_{t}-u_{t}^{*}\right)^{2}$ where $u^{*}$ is now given by equation (10). Figure 4 shows the mean error between the optimal case and the historical reaction function. Results obtained running Monte-Carlo simulations confirm the superiority of a priority on inflation in a high-volatility regime and are consistent with an equal priority in a low-volatility regime. 
Markovian Case

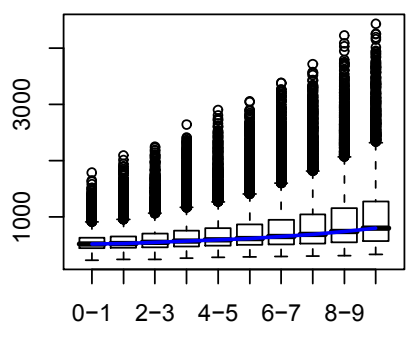

Weight on Inflation in Regime 1

Markovian Case

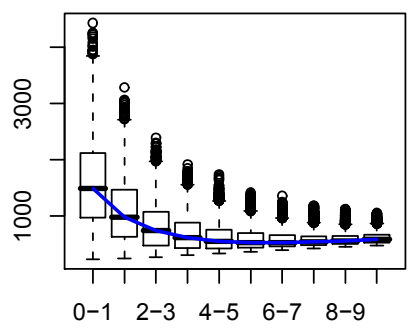

Weight on GDP in Regime 1
Markovian Case

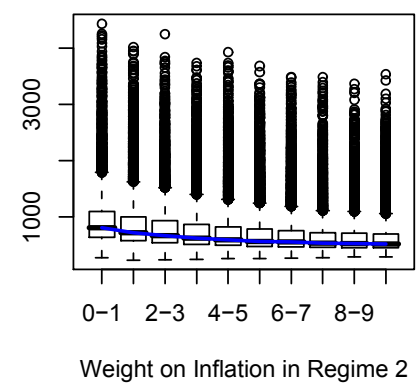

Markovian Case

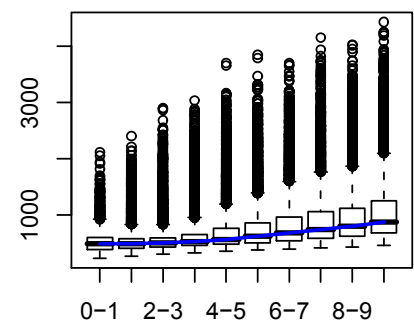

Weight on GDP in Regime 2

Figure 4: Monte Carlo simulation. Mean error between optimal and realized reaction function: (a) Simulations on inflation weights (top), (b) simulations on GDP weights (bottom)

\section{Concluding Remarks}

In this paper, we are interested in comparing optimal monetary policy to the realized interest rates. We derive the optimal monetary policy using first a deterministic framework and then a Markov Jump one. Moreover, we allow a change in preferences of the central bank, represented by the weights on inflation and output gap. Using quarterly US data over the period 19602008 , estimates of the business cycle clearly show a regime change during the early 80 's. The US quarterly data for the economy shows a switch from an inflationist regime to a more stable one. Using a deterministic model, there is no unique optimal solution that fits the behavior of the central bank over the entire period. Using a Markov Jump Linear Quadratic problem of minimization for the central bank improves the understanding of the federal funds rate dynamics. We clearly see that monetary authorities have to change their inflation/output relative preferences depending on the regime they assume the economy is following. 


\section{References}

Abou-Kandil H., Freiling G. and G. Jank (1995) "On the solution of discrete time markovian jump linear quadratic control problems", Automatica, 31(5), 765-768

Ang A. and G. Bekaert (2002), "Regime Switches in Interest Rates", Journal of Business and Economic Statistics, 20(2), 163-182.

Assenmacher-Wesche K. (2006), "Estimating Central Banks' preferences from a time-varying empirical reaction function, European Economic Review, 50, 1951-1974.

Bellone B. (2005), "Classical estimation of Multivariate Markov Switching Model with MSBVARlib", unpublished paper.

Blake A. P. and F. Zampolli (2006), "Optimal Monetary Policy in Markov-Switching Models with Rational Expectations Agents", Bank of England Working Paper \#298.

Chizeck H.J., Willsky A.S. and D. Castanon (1986), "Discrete-time Markovian Jump Linear Quadratic Optimal Control", International Journal of Control, 43(1), 213-231.

Clarida R., Gali J. and M. Gertler (2000), " Monetary Policy Rules and Macroeconomic Stability: Evidence and Some Theory", Quarterly Journal of Economics, 115(1), 147-180.

Davig T. (2004), "Regime-Switching Debt and Taxation", Journal of Monetary Economics, 51(4), 837-859.

Davig T. and E.M. Leeper (2007), "Generalizing the Taylor Principle", The American Economic Review, 97(3), pp 607-635.

Dennis R. (2004), "Inferring policy objectives from economic outcomes", Oxford Bulletin of Economics and Statistics, 66 (supplement), 735-764.

Dennis R. (2006), "The Policy Preferences of the US Federal Reserve ", Journal of Applied Econometrics, 21, 55-77.

Favero C.A. and R. Rovelli (2003), "Macroeconomic stability and the preferences of the Fed: A formall analysis, 1961-98", Journal of Money, Credit and Banking, 35(4), 545-556.

Hamilton J.D. (1988), "Rational-Expectations Econometric Analysis of Changes in Regime: An Investigation of the Term Structure of Interest Rates", Journal of Economic Dynamics and Control, 12, 385-423.

Hamilton J.D. (1989), "A New Approach to the Economic Analysis of Nonstationary Time Series and the Business Cycle", Econometrica, 57(2), 357-384.

Hamilton J.D. (2005), "What's real about the Business cycle?", Federal Reserve Bank of St. Louis Review, 87(4), 435-452. 
Judd J. P. and G. D. Rudebusch (1998), "Taylor's rule and the Fed, 1970-1997", Economic Review, 3, 3-16.

Moessner R. (2006), "Optimal discretionary policy in rational expectations models with regime switching", Bank of England Working Paper \#299.

Ozlale U. (2003), "Price stability vs. output stability: tales of federal reserve administrations", Journal of Economic Dynamics and Control, 27, 1595-1610.

Pindyck R.S. (1972), "An application of the linear-quadratic tracking problem to economic stabilization policy", IEEE Transactions on automatic control, AC-17, 287-300.

Pindyck R.S. (1973), "Optimal policies for economic stabilization", Econometrica, 41(3), 529-560.

Rudebusch G. D. (2002), "Term Structure Evidence on Interest Rate Smoothing and Monetary Policy Inertia", Journal of Monetary Economics, 49(6), 1161-1187.

Rudebusch G. D. and L.E.O. Svensson (1999), "Policy Rules for Inflation Targeting", in John B. Taylor (ed.), Monetary Policy Rules, University of Chicago Press.

Rudebusch G. D. and L.E.O. Svensson (2002), "Eurosystem monetary targeting: Lessons from U.S. data", European Economic Review, 46, 417-442.

Sims C.A. and T. Zha (2006), "Were There Regime Switches in U.S. Monetary Policy?", American Economic Review, 96:1, pp. 54-81.

Svensson, L.E.O. (1999), "Inflation targeting as a monetary policy rule", Journal of Monetary Economics, 43, 607-654.

Svensson L.E.O., and N. Williams (2007a), "Monetary Policy with Model Uncertainty: Distribution Forecast Targeting", Princeton University Working Paper.

Svensson L.E.O., and N. Williams (2007b), "Bayesian and Adaptive Optimal Policy under Model Uncertainty", NBER Working Paper, 13414.

Svensson L.E.O., and N. Williams (2008), "Optimal Monetary Policy under uncertainty: A Markov Jump Linear Quadratic approach", Federal Reserve Bank of St Louis Review, 90(4), 275-293.

Taylor J.B. (1993), "Discretion versus policy rules in practice", Carnegie-Rochester Conference Series on Public Policy, 39, 195-214.

Zampolli F. (2006), "Optimal monetary policy in a regime-switching economy: The response to abrupt shifts in exchange rate dynamics", Journal of Economic Dynamics 63 Control, 30, 1527-1567. 


\section{APPENDIX}

\section{A Optimal Reaction function in the determinist case}

\section{Constant case}
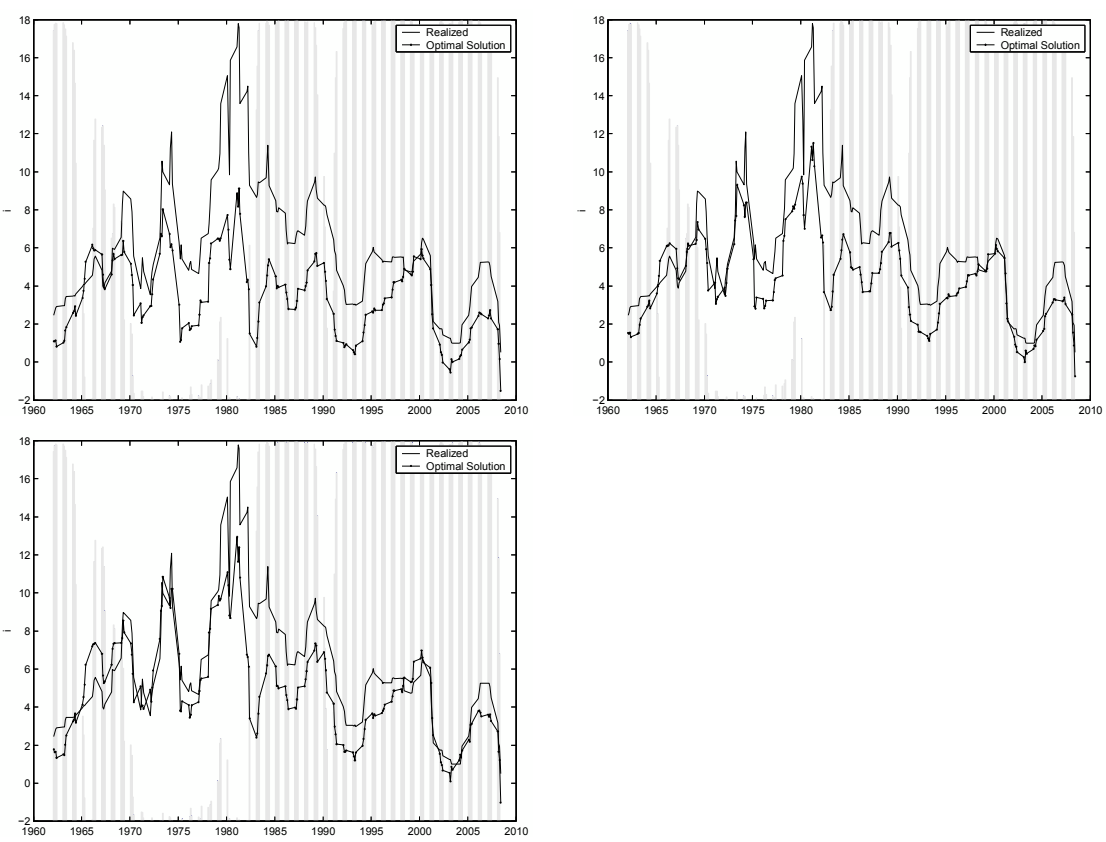

Figure A.1: Historical interest rate values versus theoretical optimal ones with (a) output gap priority (top left), (b) equal priority (top right), (c) inflation priority (bottom). The vertical bars indicate the low-volatility regime of the economy. 

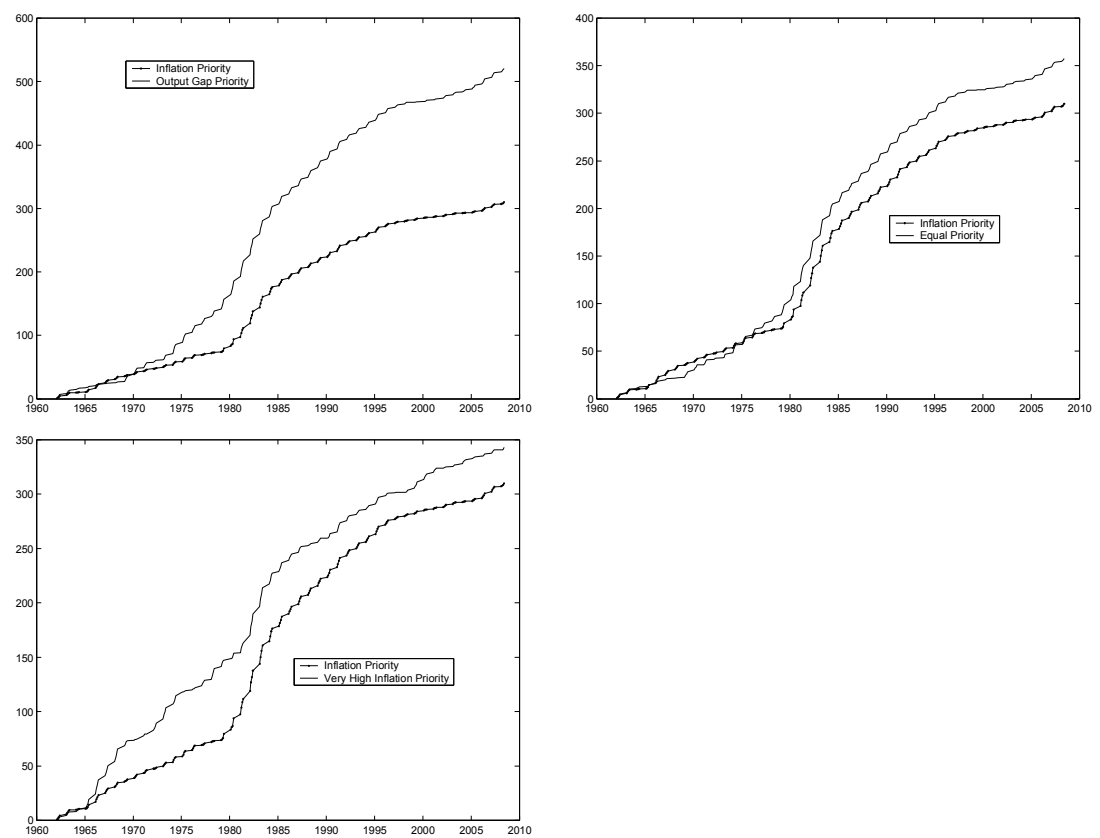

Figure A.2: Cumulative sum of absolute deviation between one-step ahead prediction and the historical interest rate. (a) Inflation versus output gap priority (top left), (b) Inflation priority versus equal priority (top right), (c) Inflation priority versus very high inflation priority (bottom).

\section{Low-volatility regime}
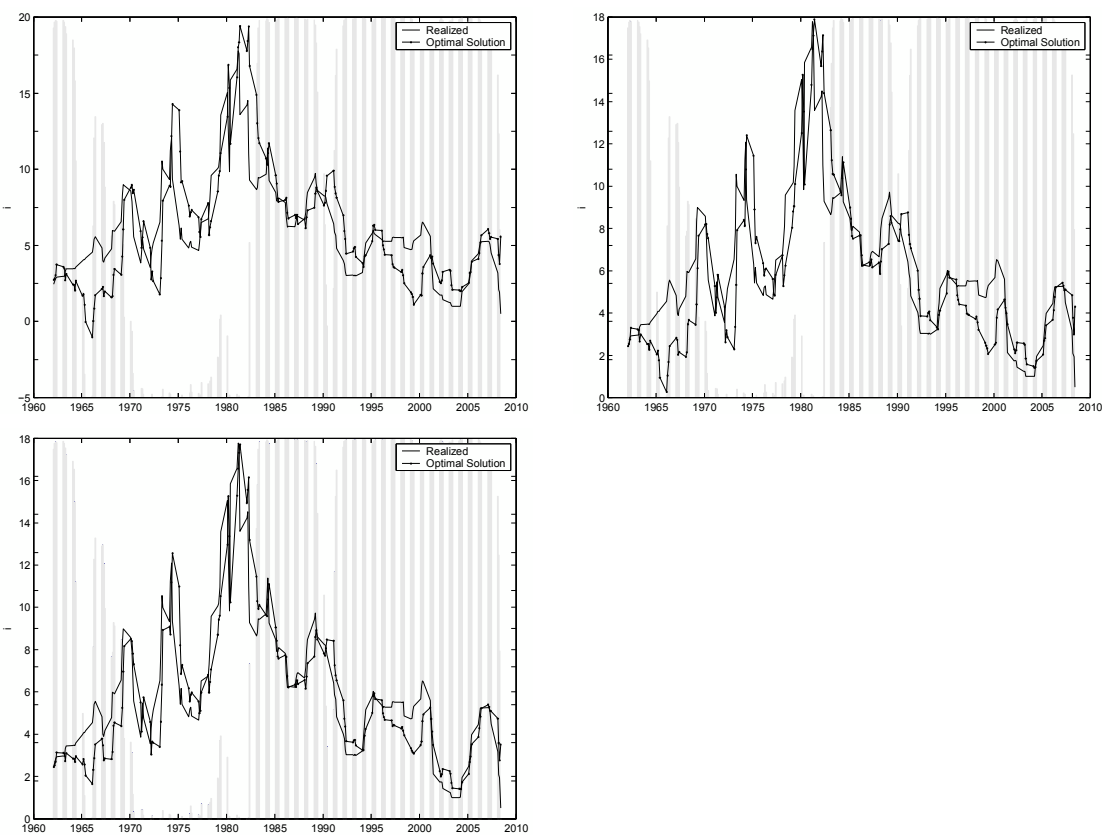

Figure A.3: Historical interest rate values versus theoretical optimal ones with (a) Output gap priority (top left), (b) equal priority (top right), (c) inflation priority (bottom). The vertical bars indicate the low-volatility regime of the economy. 

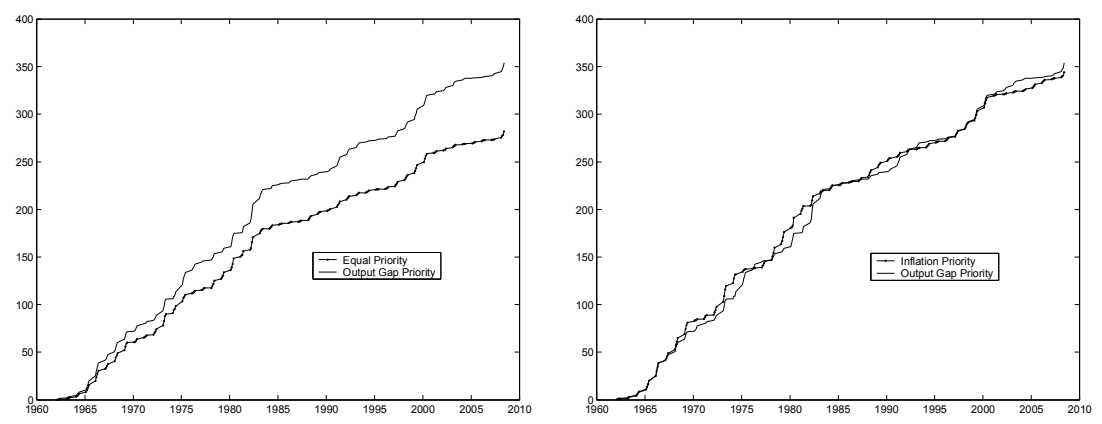

Figure A.4: Cumulative sum of absolute deviation between one-step ahead prediction and the historical interest rate. (a) Equal priority versus output gap priority (left). (b) Inflation priority versus output gap priority (right)
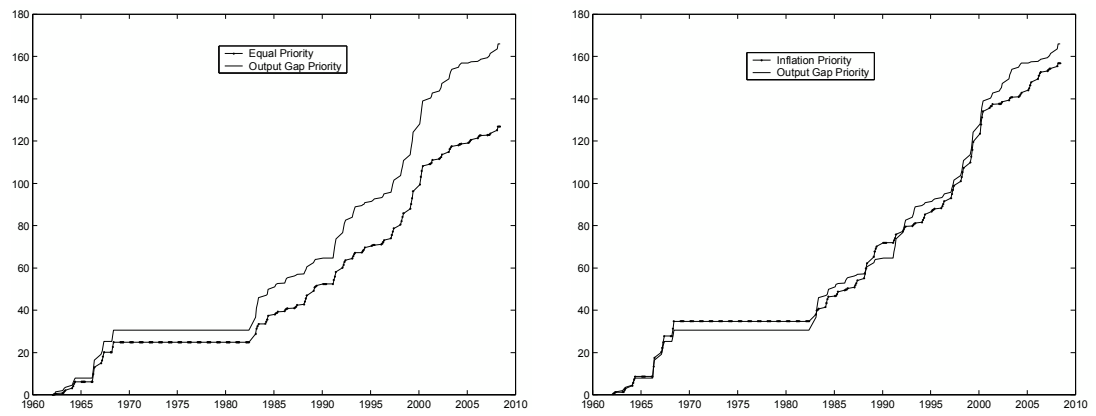

Figure A.5: Cumulative sum of absolute deviation between one-step ahead prediction and the historical interest rate (low-volatility regime). (a) Equal priority versus output gap priority (left). (b) Inflation priority versus output gap priority (right) 


\section{High-volatility regime}
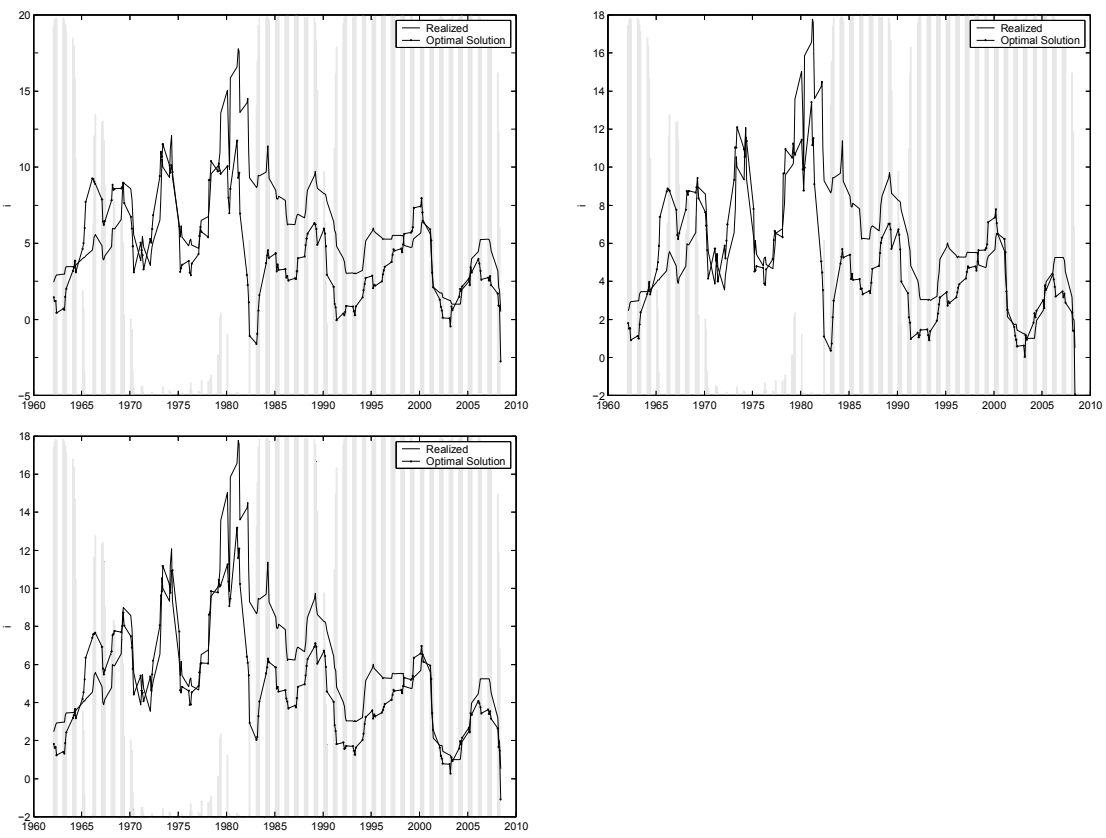

Figure A.6: Historical interest rate values versus theoretical optimal ones with (a) Output gap priority (top left), (b) equal priority (top right), (c) inflation priority (bottom). The vertical bars indicate the low-volatility regime of the economy. 

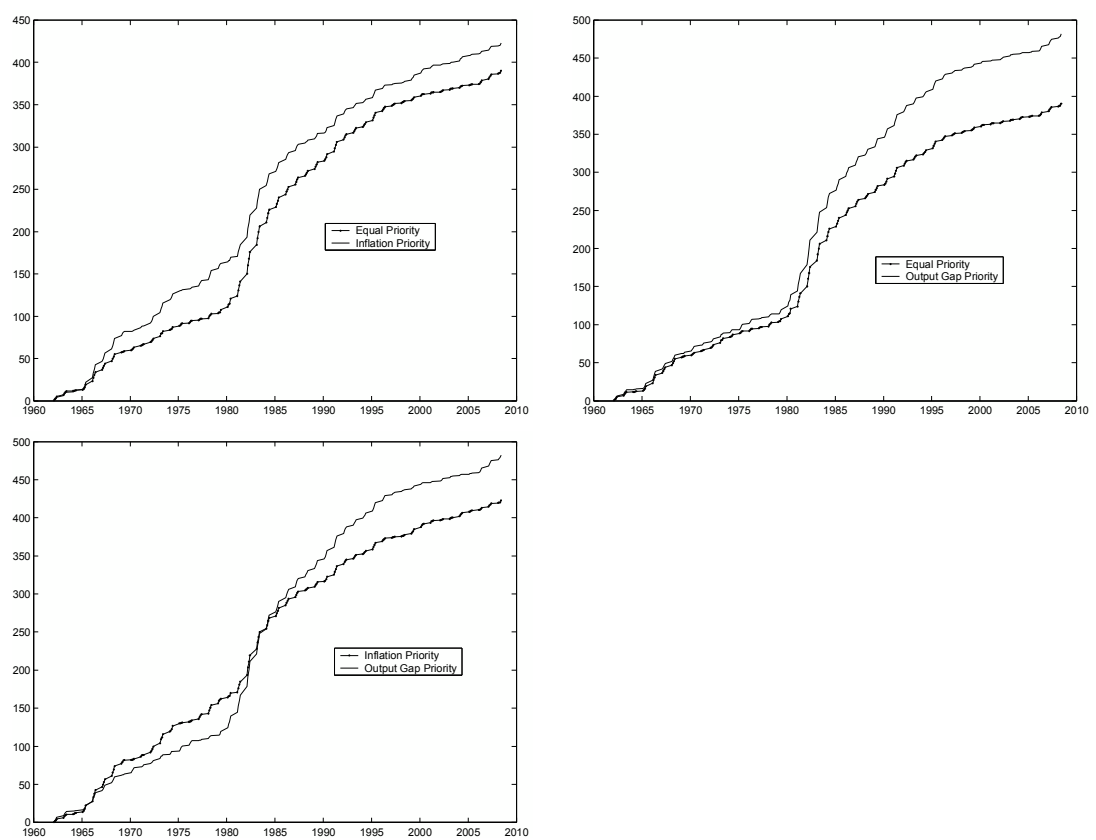

Figure A.7: Cumulative sum of absolute deviation between one-step ahead prediction and the historical interest rate. (a) Inflation priority versus equal priority (top left). (b) Equal priority versus output gap priority (top right). (c) Inflation priority versus output gap priority (bottom)
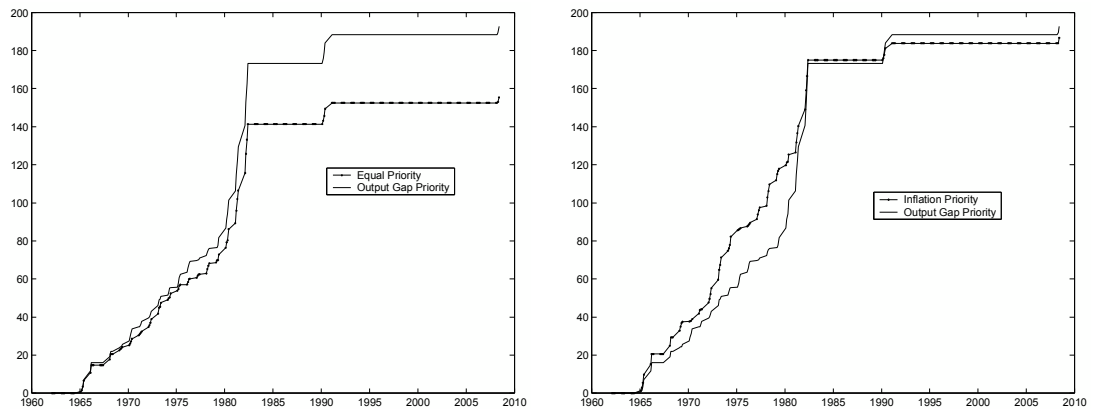

Figure A.8: Cumulative sum of absolute deviation between one-step ahead prediction and the historical interest rate (high-volatility regime). (a) Equal priority versus output gap priority (left). (c) Inflation priority versus output gap priority (right) 


\section{B Optimal Reaction function in the MJLQ case}
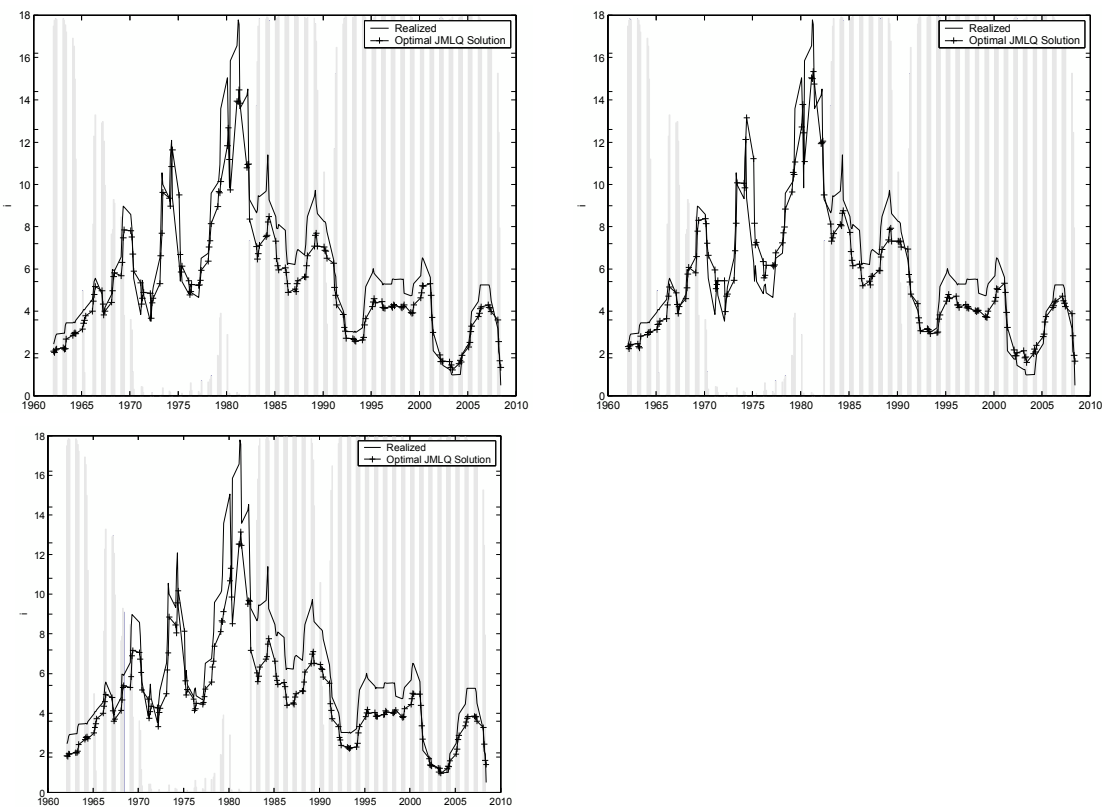

Figure B.1: Evolution of the realized versus the optimal stable state solution: (a) neutral case (top left), (b) output-low/inflation-high (top right), (c) inflation-low/output-high (bottom).

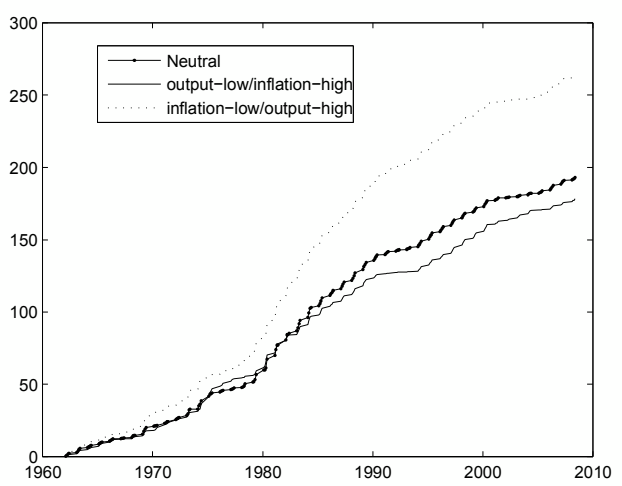

Figure B.2: Cumulative sum of absolute deviation between one-step ahead prediction and the historical interest rate. Neutral case vs output-low/inflation-high and inflation-low/outputhigh. 


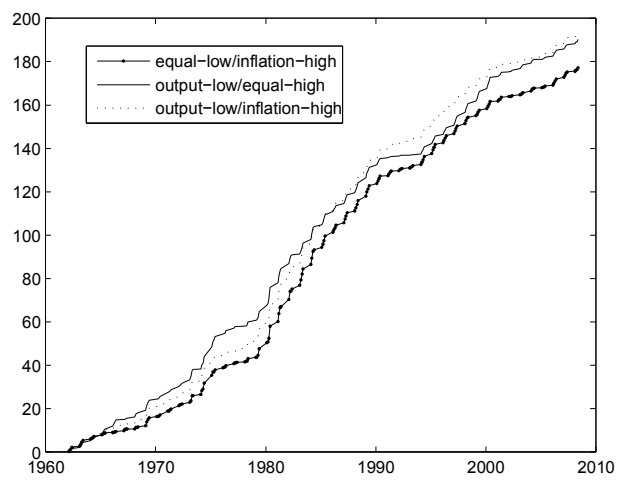

Figure B.3: Cumulative sum of absolute deviation between one-step ahead prediction and the historical interest rate. Output-low/inflation-high vs equal-low/inflation-high and outputlow/equal-high. 